\title{
Effective composite binders
}

\author{
Nataliya Ivanovna Alfimova \\ Department of construction materil science, subjects and \\ structures \\ Belgorod State Technological University \\ named after V.G. Shoukhov \\ BSTU named after V.G. Shoukhov \\ Belgorod, Russia \\ alfimovan@mail.ru \\ Anatoliy Mitrofanovich Gridchin \\ Department of roads and railways \\ Belgorod State Technological University \\ named after V.G. Shoukhov \\ BSTU named after V.G. Shoukhov \\ Belgorod, Russia \\ Evgeniy Sergeevich Glagolev \\ Department of construction and minicipal engineering \\ Belgorod State Technological University \\ named after V.G. Shoukhov \\ BSTU named after V.G. Shoukhov \\ Belgorod, Russia
}

\author{
Ruslan Valerievich Lesovik \\ Department of construction materil science, subjects and \\ structures \\ Belgorod State Technological University \\ named after V.G. Shoukhov \\ BSTU named after V.G. Shoukhov \\ Belgorod, Russia
}

Olga Viktorovna Levchenko

Department of construction materil science, subjects and structures

Belgorod State Technological University

named after V.G. Shoukhov

BSTU named after V.G. Shoukhov

Belgorod, Russia

Sevda Iunisovna Pirieva

Department of construction materil science, subjects and structures

Belgorod State Technological University

named after V.G. Shoukhov

BSTU named after V.G. Shoukhov

Belgorod, Russia

\begin{abstract}
Nowadays, many countries of the world are witnessing the tendency of refocusing the building materials industry upon the types of concrete, whose distinguishing characteristic is the reduced consumption of portland cement. The studies aimed to develop effective composite binders and expand the raw materials base for their manufacturing are also becoming rather relevant. From this perspective, the products of volcanic activity are of special interest due to their high concentration all over the world. The largest cluster of this raw material in the Russian Federation is located in the Kamchatka peninsula. For this reason, the research on finding optimal technological parameters of manufacturing fine ground cement with the application of igneous-sedimentary rock of the Kamchatka peninsula was carried out. The obtained results enabled revealing the dependencies (compression resistance and time for manufacturing binders on the quantity and initial surface area of the igneous-sedimentary rocks), allowing one to optimize the parameters of manufacturing fine ground cement together with providing maximum rigidity at minimum power costs required for its grinding.
\end{abstract}

Keywords - composite binders, volcanic material, energy preservation, grinding, rheology

\section{INTRODUCTION}

Energy preservation and sustainable use of natural resources form the priority area of construction material development all over the world. Acceleration of these tendencies is connected not only with the integrated involvement of raw material resources into the process of manufacturing but also with the search for new ones, which use could enable one not only to apply the energy of geological processes but also to orient this energy to their foundation $[1,2]$

The products of volcanic activity are of special interest from this standpoint. The most significant reason for it is the fact that while possessing the surplus stockpile of internal energy, they will not only reduce the energy intensity during the manufacturing process but also advance quality improvement of the construction material [3-8]. Secondly, the amount of volcanic activity products all over the world is currently equal to billion tons. The Kamchatka peninsula is the most perspective territory in the Russian Federation from the perspective of the raw materials source.

Complex research of igneous-sedimentary rocks (ISR) of the Kamchatka peninsula has proved the appropriateness of their usage as the components of composite binders (CB), such as fine ground cement (FGC). The efficiency of FGC was proved by numerous researches and it is primarily stipulated by the opportunity to replace a considerable part of the brick constituents with the silica-containing ones and by developing special properties in cements manufactured with the use of identical binders [6-20]. However, composite binders mainstreaming restricts the questions connected with the 
considerable energy consumption aimed at their production by means of components grinding.

Nowadays, re-grinding commercial portland cement with additives is the most widely implemented method of manufacturing composite binders (CB). However, a set of factors having a great impact on the speed of grinding and activity of the obtained binders is not taken into consideration. These factors are as follows: rigidity, granulometry and the ratio of the mixture components, as well their ability to form aggregates [21, 22].

Therefore, the research aimed to optimize required compound technological parameters of manufacturing FGC with the use of igneous-sedimentary rock was conducted.

\section{METHODS}

Zhirovskoy Volcano activity products being the sand of bright grey colour and the packed density equal to $1150 \mathrm{~kg} / \mathrm{m}^{3}$, which size modulus equals 3.64 , and the most representative faction equal to 2.5 were the objects of research. The major rock-forming minerals of the stated raw material are albite and clay minerals; the major chemical compounds are silicon and aluminic oxides. These rocks are characterized by polydisperse distribution of particles which size varies from 1 to $350 \mu \mathrm{m}$. The particles differ by an inhomogeneous surface, which is mostly covered with finely divided products of coarse particles degradation.

Fine ground cements were produced in a laboratory vibration mill. The cements were ground according to single(mixed - grinding all the components after their concurrent loading into the mill) and two- (separable - re-grinding ISR to the degree of the stated surface area with the following additional loading of Portland and their mixed grinding up to $500 \mathrm{~m}^{2} / \mathrm{kg}$ ) stages schemes.

Optimization of required compound technological parameters of producing composite binders with the use of Kamchatka ISR was implemented with the help of the mathematical experimental design method. The amount of igneous-sedimentary rocks in the mixture and their initial grinding fineness acted as variation factors (Table 1).

TABLE I. EXPERIMENTAL DESIGN REQUIREMENTS

\begin{tabular}{|c|c|c|c|c|c|}
\hline \multicolumn{2}{|l|}{ Factors } & \multicolumn{3}{|c|}{ Variation levels } & \multirow{2}{*}{$\begin{array}{l}\text { Variation } \\
\text { intervals }\end{array}$} \\
\hline Natural form & Coded form & -1 & 0 & 1 & \\
\hline $\begin{array}{l}\text { ISR amount, as \% of } \\
\text { composite binders weight }\end{array}$ & $\mathrm{X}_{1}$ & 30 & 50 & 70 & 20 \\
\hline ISR surface area, $\mathrm{m}^{2} / \mathrm{kg}$ & $\mathrm{X}_{2}$ & 300 & 400 & 500 & 100 \\
\hline
\end{tabular}

Compression resistance and the time of grinding composite binders were chosen to be the output parameters.

Processing the obtained results by means of the method of experiment mathematic design enabled one to draw regression equations, which assisted in defining the dependence of the compression resistance and the grinding time on the varying factors.

The particles surface morphology was studied with the application of a scanning electron microscope of high resolution TESCAN MIRA 3 LMU, including energy-disperse spectrometer X-MAX 50 Oxford Instruments NanoAnalysis.

Changing the apparent viscosity and the shear rate of the fine-grind cements (FGC-50 and FGC-70) was studied with the help of installing the rotary viscometer "Rheotest-2" with coaxial cylinders. FGC suspensions with similar values $\mathrm{V} / \mathrm{T}=0.4$ were taken.

\section{MAIN PART}

As it was noted above, a set of factors will have impact on the grinding speed and the composite binders' activity. Thus, the components with a more constant particles' size rather than the ones with a diverse particle composition will be less subject to aggregating; herewith, the better the degree of grinding material is, the higher will be its tendency to aggregation. Additionally, it is vital to consider the interaction processes of mixture ingredients, which will also depend on the rigidity and components tendency for aggregation. For this reason, the volcanic material grinding capacity was studied at the first stage of the research. Surface areas of 300, 400 and $500 \mathrm{~m}^{2} / \mathrm{kg}$ served as check points. The analysis of the obtained results showed that the grinding capacity of ISR is larger in comparison with that of the quartz sand taken by the specimen, herewith, the time required for achieving the desired surface area decreases 3 times. A larger grinding capacity of igneous-sedimentary rock is stipulated by lower rigidity adherent to the composing minerals in comparison with the quartz being the main constituent of the natural sand as well as lower rigidity of the contact surface of the materials, which form the material under consideration and which is compositionally polymineral.

Studying the impact of the surface area on altering the qualitative characteristics of the igneous-sedimentary rock allowed stating that the quantity of tiny particles increases with the growth of fineness of the material under consideration from 300 to $500 \mathrm{~m}^{2} / \mathrm{kg}$; however, the pattern of their distribution remains the same. Herewith, grains of ISR with the surface area equal to $300 \mathrm{~m}^{2} / \mathrm{kg}$ have a rounded form in comparison with the grains of quartz sand (control specimen) with the same grinding fineness; however, there is the tendency of growing angularity and isometricity of its grains of coarse and fine fraction with the growth of fineness (Fig.1). 

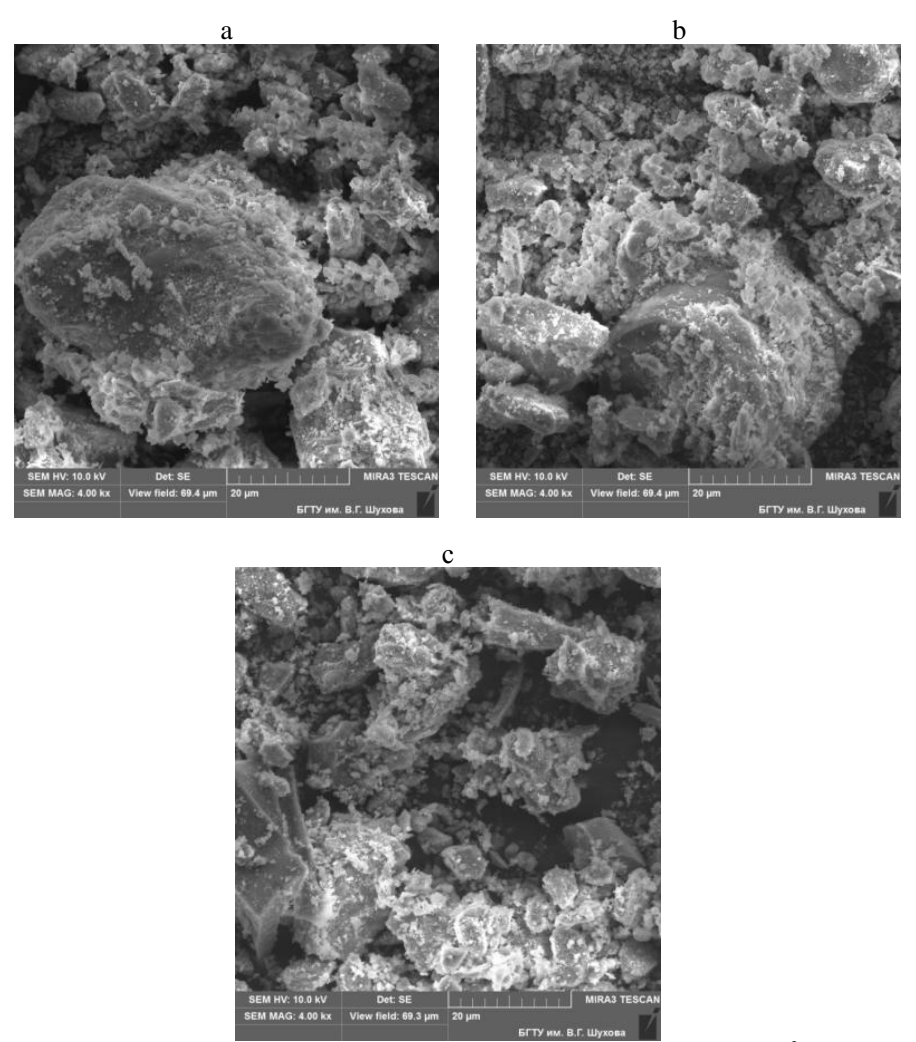

Fig. 1. Morphology of ISR part in terms of surface area a $-300 \mathrm{~m}^{2} / \mathrm{kg} ; \mathrm{b}-$ $400 \mathrm{~m}^{2} / \mathrm{kg} ; \mathrm{c}-500 \mathrm{~m}^{2} / \mathrm{kg}$

The obtained results enable one to conclude that the second component in the system "portland cement - igneoussedimentary rock" possesses the higher grinding capacity, which will have an impact on the processes of the components interaction when producing fine ground cement with the use of this material.

Further research was aimed to detect the previously stated principles with the application of the mathematical experimental design method (Table I).

Analysis of the impact of varying factors on the output parameters in the process of manufacturing fine ground cement with the use of igneous-sedimentary rock led to the conclusion that the time spent on obtaining binders of the stated surface area regardless of the grinding method increases when the content of portland cement rises from 30 to $50 \%$, which is stipulated by its greater rigidity (Table II). However, the further increase of the brick constituent up to $70 \%$ resulted in the reduction of time spent on grinding, which can be reasoned by the reduced amount of ISR being the component, subject to aggregation, and the increase of the amount of portland cement being a more rigid component.
TABLE II. CHARACTERISTICS OF FGC PRODUCED WITH USE OF ISR DEPENDING ON GRINDING METHOD

\begin{tabular}{|c|c|c|c|c|c|c|c|c|}
\hline \multicolumn{3}{|c|}{ FGC-30 } & \multicolumn{3}{|c|}{ FGC -50 } & \multicolumn{3}{|c|}{ FGC -70 } \\
\hline $\begin{array}{l}\text { Ssurf, } \\
\mathrm{m}^{2} / \mathrm{kg}\end{array}$ & $\begin{array}{l}\mathrm{T}^{*}, \\
\text { min }\end{array}$ & $\begin{array}{c}\text { Rcompr, } \\
\text { MPa }\end{array}$ & $\begin{array}{l}\text { Ssurf, } \\
\mathrm{m}^{2} / \mathrm{kg}\end{array}$ & $\begin{array}{l}\mathrm{T}^{*}, \\
\mathrm{~min}\end{array}$ & $\begin{array}{c}\text { Rcompr, } \\
\mathrm{MPa}\end{array}$ & $\begin{array}{l}\text { Ssurf, } \\
\mathrm{m}^{2} / \mathrm{kg}\end{array}$ & $\begin{array}{l}\text { T*, } \\
\text { min }\end{array}$ & $\begin{array}{c}\text { Rcompr, } \\
\text { MPa }\end{array}$ \\
\hline \multicolumn{9}{|c|}{ Single-stage grinding } \\
\hline 532 & 21 & 14,02 & 524 & 25 & 27,98 & 533 & 29 & 37,50 \\
\hline \multicolumn{9}{|c|}{ Two-stage grinding } \\
\hline \multicolumn{9}{|c|}{ ISR surface area $300 \mathrm{~m}^{2} / \mathrm{kg}$} \\
\hline \multirow{2}{*}{526} & 12 & \multirow{2}{*}{13.05} & \multirow{2}{*}{526} & 17 & \multirow{2}{*}{30.11} & \multirow{2}{*}{523} & 15 & \multirow{2}{*}{34.06} \\
\hline & 7 & & & 4 & & & 1 & \\
\hline \multicolumn{9}{|c|}{ ISR surface area $400 \mathrm{~m}^{2} / \mathrm{kg}$} \\
\hline \multirow{2}{*}{523} & 11 & \multirow{2}{*}{11.78} & \multirow{2}{*}{527} & 15 & \multirow{2}{*}{27.01} & \multirow{2}{*}{533} & 14 & \multirow{2}{*}{35.88} \\
\hline & 9 & & & 6 & & & 2 & \\
\hline \multicolumn{9}{|c|}{ ISR surface area $500 \mathrm{~m}^{2} / \mathrm{kg}$} \\
\hline \multirow{2}{*}{532} & 13 & \multirow{2}{*}{10.69} & \multirow{2}{*}{524} & 14 & \multirow{2}{*}{25.86} & \multirow{2}{*}{530} & 14 & \multirow{2}{*}{32.98} \\
\hline & 11 & & & 8 & & & 3 & \\
\hline
\end{tabular}

Analysing the influence of the grinding method on the composite binder compression resistance has shown that FGC70 and FGC-30 produced by the method of mixed grinding differ by slightly larger values of the given indicator in comparison to the same composite binders produced with the two-stage grinding scheme. On the other hand, FGC-50 is characterized by a greater value of rigidity of the binder produced on the basis of the two-stage grinding scheme with ISR re-grinding up to $300 \mathrm{~m}^{2} / \mathrm{kg}$.

It was also found that in case of separate grinding the rigidity under compression decreases with the growth of the initial ISR surface area. It is stipulated by the fact that the time spent on mixed grinding of binder components decreases with the increase of ISR fineness and, consequently, cement particles grinding fineness decreases as well, which leads to the decrease of compression resistance when compressing composite binders.

It is worth stating that the time of producing composite binders and, consequently, energy intensity decrease with the application of the separate grinding method regardless of the mixture ratio. Thus, when producing FGC-30, the length of grinding falls at an average rate by $43 \%$, FGC-50 - by $36 \%$ and FGC-70 - by $51 \%$. This is due to the decrease of negative impact of particle aggregation when applying a two-stage grinding scheme in the process of $\mathrm{CB}$ manufacturing.

Thus, when applying separate grinding technology for producing FGC-30 and FGC-50, re-grinding ISR up to 300 $\mathrm{m}^{2} / \mathrm{kg}$, and FGC-70 up to $400 \mathrm{~m}^{2} / \mathrm{kg}$ is more sensible with regard to gaining optimal values of output parameters.

Analysing the microstructure of fine ground cements produced by single- and two-stage schemes has led to finding the differences in the nature of obtained materials. The foremost prominent entities are adherent to FGC-70, which is due to the large concentration of brick constituents.

Analysis of the morphology of the newly obtained FGC-70 has shown that the specimens produced with the application of single - (Fig. 2a) and two-stage technology with re-grinding ISR up to $300 \mathrm{~m}^{2} / \mathrm{kg}$ (Fig. $1 \mathrm{~b}, 1 \mathrm{c}$ ) are characterized by a rather homogeneous structure. Additionally, the dense mixture consists of amorphous newly obtained materials that are 
weakly cut, poorly decrystallined by X-ray, while CB holes are filled with rather well-shaped oblong crystals, which connect cell walls (Fig. 2a, b). The foremost prominent system of newly obtained materials is adherent to $\mathrm{CB}$ produced via mixed component grinding (Fig. 2, $2 \mathrm{a}-\mathrm{c}$ ).
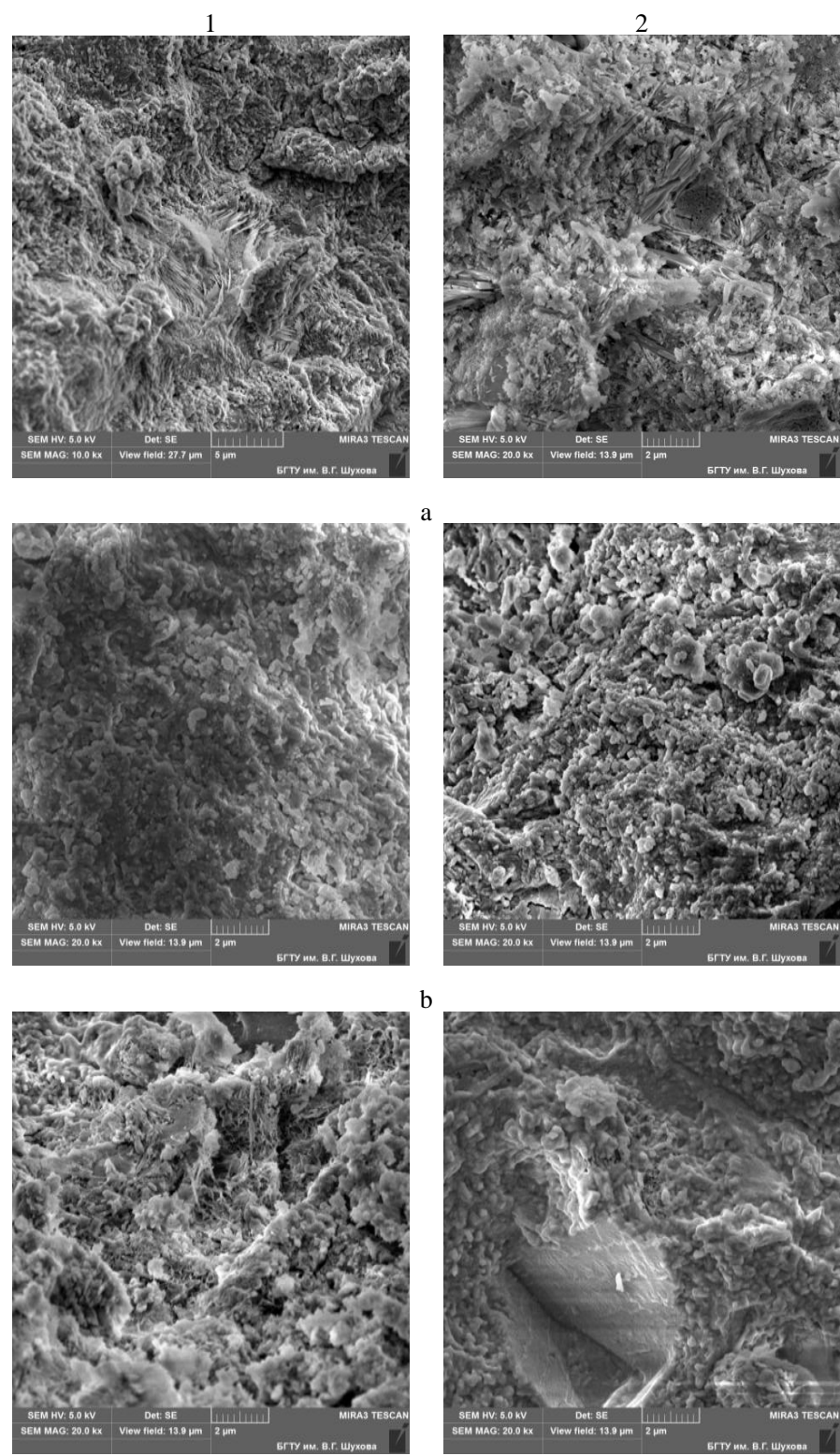

Fig. 2. Microstructure FGC-70 (a); FGC -50 (b); FGC -30 (c), produced with the application of ISR via sinlge-stage (1) and two-stage production scheme (2)

At the same time, specimens FGC-70 (Fig. 2a) produced using the two-stage technology with re-grinding of ISR up to $500 \mathrm{~m}^{2} / \mathrm{kg}$ are characterized by a porous structure represented by X-ray amorphous newly obtained materials. It is stipulated by the fact that a considerable enlargement of the surface area of ISR having a greater grinding capacity under the conditions of grinding with portland cement poses negative effect on its surface area, which, in its turn, forwards the reduction of its reactive capacity in comparison with the binders produced in an alternative way.
Analysis of X-ray diagrams of composite binders with the application of ISR has shown that regardless of the grinding method the rates of portlandite and brick minerals are virtually identical with a slight decline in case of $\mathrm{CB}$, gained with the mixed grinding (Fig.3).

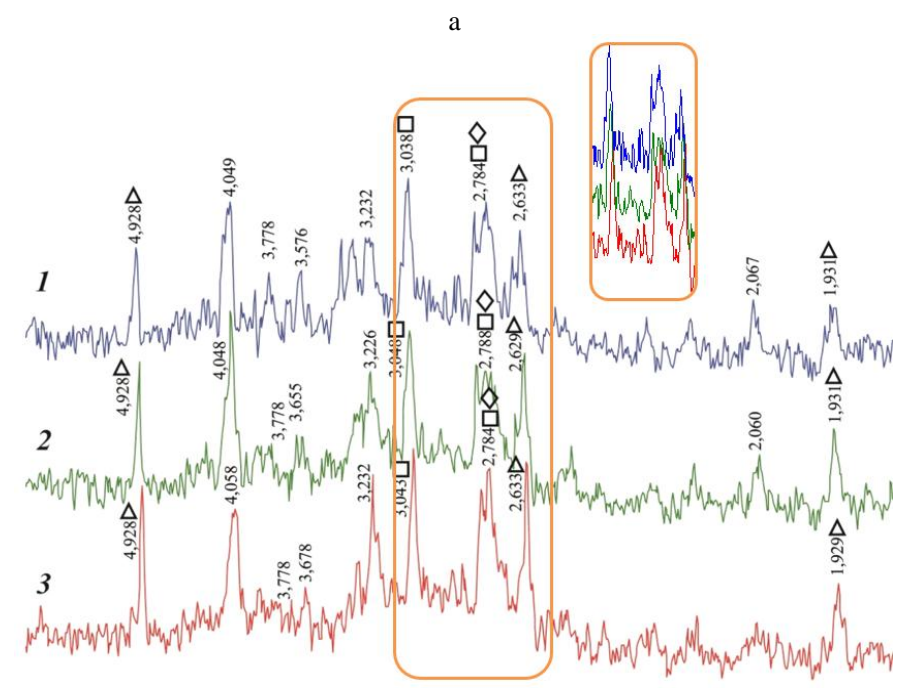

$\mathrm{b}$

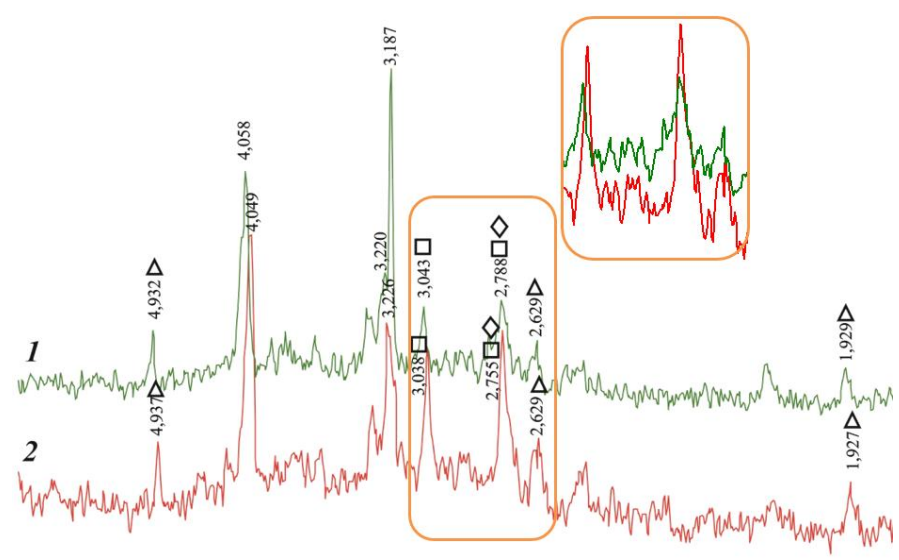

$\square-\mathrm{C} 3 \mathrm{~S} ; \diamond-\mathrm{C} 2 \mathrm{~S} ; \Delta-\mathrm{Ca}(\mathrm{OH}) 2$

Fig. 3. FGC-70 (a), FGC-50 (b), produced with single- (1) and two-stage scheme with re-grinding ISR up to $300 \mathrm{~m}^{2} / \mathrm{kg}$ (2); $400 \mathrm{~m} / \mathrm{kg}$ (3)

Thus, it was stated that application of two-stage technology decreases the negative influence of the processes stipulated by the difference in qualitative characteristics (granulometry, grinding capacity, aggregation) of the constituents.

Proceeding from the position that rheological characteristics of suspensions play a crucial role in manufacturing concrete for various applications, the research aimed to study the effect of grinding method and the content on changing the apparent viscosity, FGC-50 and FGC-70 shear rate was conducted. Binders produced according to 
analogous technological parameters based on quartz sand acted as control positions.

When analyzing the effect of $\mathrm{CB}$ grinding methods on their rheology, it was stated that regardless of the genesis of silica component, the FGC produced with the single-stage technology are characterized by smaller viscosity indicators. It can be explained by the fact that the $\mathrm{CB}$ production method influences the qualitative characteristics of ISR components and, in particular, separate grinding facilitates a more qualitative components dispersion, which promotes the formation of a more rigid coagulation structure at the expense of free bonds' growth.

It was stated as well that regardless of the method of grinding FGC-50, produced with the use of ISR in comparison with FGC-70, which is characterized by lower viscosity indexes. This discrepancy for binders produced under the conditions of separate grinding is equal to $32 \%$; under the mixed one - to $36 \%$, which is stipulated by the decrease of the amount of portland cement in the system.

In the meantime, a somewhat different dependency was evidenced while studying the rheograms of fine ground cements produced with the use of quartz sand (control structure). Thus, under the conditions of the components' separate grinding, slightly larger viscosity indexes were adherent to FGC-50, while the mixed grinding method raised the viscosity indexes of FGC-70. This also proves that separate grinding facilitates more qualitative dispersion of quartz particles and the growth of bonds between them by increasing the system viscosity through decreasing the amount of its brick constituents. However, it is worth stating that this discrepancy is rather small and is equal to less than $1 \%$.

Thus, when analysing the effect of the silica component genesis on the rheology of $\mathrm{CB}$, it was stated that regardless of the manufacturing method and the amount of brick constituents in the mixture, the FGC produced with the use of ISR are characterized by a greater viscosity index in comparison with FGC, based on quartz sand. It is stipulated by the fact that ISR, characterized by lower rigidity in comparison to the quartz sand in $\mathrm{CB}$, are re-ground to a higher surface area. As a result, the amount of absorptive bind increases and the amount of free fluid decreases, which leads to system viscosity growth. Concurrently, adsorption film decreases intermolecular interaction and adhesive power between particles by weakening coagulative contacts, which facilitates system fluidization under the influence of outer mechanical effect and its recovery after the influence is stopped. It stipulates the narrowing of hysteresis loop of $\mathrm{CB}$ produced with ISR. It is worth stating that low system structuredness is more preferable from the technology viewpoint.

It was stated as well that viscosity indexes of the fine ground cements are lower than the ones of the portland cement regardless of the altering technological factors (production technology, the type and the amount of the silica constituent), which is positive for energy intensity of the process of manufacturing goods with the use of the given type of FGC.
The obtained principles concern the impact of the method of the genesis grinding of the silica component and its amount on rheological characteristics of $\mathrm{CB}$, which are crucial from the technology process viewpoint and they need to be taken into account during the mix agitation, transformation, formation, etc.

One of the major CB applications can be the production of walling items of small piece.

It is commonly known that angles and inter vacuum partitions can be damaged and sometimes such items can be even completely destructed at the stage of demolding and further transported to the solidifying post. It is possible to solve this problem and, as a result, improve the quality of items by increasing molded green strength.

According to literature data, it is recommended to tip and stack the as-formed items under the conditions of rigidity not lower than $0.2 \mathrm{MPa}$; however, it is not enough for eliminating defects.

The earlier obtained data on the influence of ISR on the rheology of water-binding systems enabled one to assume that ISR have a positive impact on raw product strength.

Therefore, the research on identifying the influence of $\mathrm{CB}$, based on ISR of Kamchatka, on the green strength was conducted. For that purpose, cylindrical specimens of the manufacturing staff were molded.

The analysis of the obtained results has shown that the surplus of the green strength with the use of FGC-70, based on ISR, is about 44-47\% in comparison with the control specimens, produced on portland cement.

This green strength surplus is stipulated by the fact that $\mathrm{CB}$, based on ISR, is represented by the particles of the size smaller than those of cement, which facilitates the expansion of the number of contacts and enhances mechanical linkage between them.

\section{CONCLUSION}

The conducted research enabled one to formulate the principles focusing on optimizing technological parameters of producing fine ground cement. These principles indicate that regardless of the varying factors (the amount of ISR and their surface area), the $\mathrm{CB}$, produced under the conditions of separate (two-stage) technology, are characterized by a lesser length and energy intensity of the manufacturing process.

The technology of producing fine ground cements with the use of ISR of Kamchatka, implying the preliminary dispersion of ISR up to the surface area, equal to $300 \mathrm{~m}^{2} / \mathrm{kg}$ with its further grinding with portland cement up to $500 \mathrm{~m}^{2} / \mathrm{kg}$, was introduced after the consideration of the obtained principles.

It was stated that the application of ISR as the component of fine ground cements led to the reduction of viscosity and structuring the system "water-binder". This, in its turn, facilitates a better molding capacity of the concrete produced with the use of the given type of binders. Additionally, the extended particles' surface predetermines the multiplication of contacts and mechanical linkage between the particles through 
tightening by providing the high degree of green strength, which, consequently, will considerably decrease the defect when manufacturing items and will enable one to produce hollow core items with the high quality of the surface area and the precise geometric pattern.

\section{Acknowledgment}

This work is realized under financial support of the Ministry of Education and Science of the Russian Federation, Federal Action Program «Research and Development in Priority Fields of Science and Technology of Russian Federation for 20142020», unique agreement identifier RFMEFI58317X0063, using equipment of the High Technology Center at BSTU named after V.G. Shoukhov.

\section{References}

[1] V.S. Lesovik, "Improving the efficiency of the production of building materials taking into account the genesis of rocks. Moscow, Publishing House Association of construction universities, 2006, p.112

[2] V.S. Lesovik, "Geonics. Subjectandobjectives," Belgorod State Technological University named after V.G. Shoukhov, 2012, p. 100

[3] P.V. Trunov, N.I. Alfimova, V.S. Lesovik, V.V. Potapov and E.E. Shadsky, "To a question about the use of raw materials of volcanic Kamchatka as a mineral additive," J. Bulletin of BSTU named after V.G. Shukhov, vol. 4, pp. 85-90, 2014.

[4] N.I. Alfimova, N.N. Shapovalov, E.E. Shadskiy and T.G., Yurakova, "Improving the efficiency of use of the products of volcanic activity," J. Bulletin of BSTU named after V.G. Shukhov, vol. 5, pp. 11-14, 2015.

[5] R.V. Lesovik, M.S. Ageeva and M. Shakarna, "Efficient binding using composite tuffs of the middle east," J. World Applied Sciences Journal, vol. 24(10), pp. 1286-1290, 2013.

[6] N.I. Alfimova, E.E. Shadskiy, R.V. Lesovik and M.S. Ageeva, "Organic-mineral modifier on the basis of volcanogenic-sedimentary rocks," J. International Journal of Applied Engineering Research, vol. 10(24), pp. 45131-45136, 2015

[7] V.S. Lesovik, L.A. Suleymanova, and K.A. Kara, "Energy efficient aerated concrete on composite binders for monolithic building," J. News of higher educational institutions Building, vol. 3, pp.10-20, 2012.

[8] O.V. Kovalchenko and N.I. Alfimova "The question of the application of products of volcanic activity in the material science," J. Bulletin of BSTU named after V.G. Shukhov, vol. 6, pp. 24-28, 2017.

[9] K.A. Kara and A.G. Suleymanov, "Aerated concrete in the composite binder using crushed limestone screenings," J. Bulletin of BSTU named after V.G. Shukhov, vol. 5, pp.64-66, 2013.
[10] L.A. Suleymanova, V.S. Lesovik, K.A. Kara M.V. Malyukova and K.A. Suleymanov, "Energy-efficient concretes for green construction," J. Research Journal of Applied Sciences, vol. 9(12), pp. 1087-109, 20140.

[11] G.G. Il'inskaya, V.S. Lesovik, L. Kh. Zagorodnyuk and A.S. Kolomatskiy, "With Dry mixes for finishing work on composite binders," J. Bulletin of BSTU named after V.G. Shukhov, vol. 4, pp. 1519, 2012.

[12] G.G. Il'inskaya, D.M. Sopin, V.A. Bogussevich, G.A. Lesovik and M. F. Circassians, "Dry finishing mixes on the basis of composite binders for the device heat-insulating systems," J. Bulletin of BSTU named after V.G. Shukhov, vol. 6, pp. 139-143, 2015.

[13] E.A. Pospelova, M.Y. Elistratkin and D.D. Netsvet, "Statistical analysis as an instrument for improving the quality of products from cellular concrete," J. Applied Mechanics and Materials, vol. 670-671, pp. 1624 1628,2014

[14] V.S. Lesovik, N.I. Alfimova, A.V. Savin., Ginzburg A.V. and N.N Shapovalov, "Assessment of passivating properties of composite binder relative to reinforcing steel," J. World Applied Sciences Journal, vol. 24 (12), pp. 1691-1695, 2013.

[15] M.S. Ageeva, D.M. Sopin, G.A. Lesovik A.A. Metrohin, Kalashnikov N.V., and V.A. Bogusevich, "The modified composite slag-cement binder," J. ARPN Journal of Engineering and Applied Sciences, vol. 9(8), pp. 1381-1385, 2014.

[16] R.V. Lesovik, A.N. Nosova, A.V. Savin and E.V. Fomina, "Assessment of the suitability of the opal-cristoballite rocks of korkinsk deposit in the construction industr," J. World Applied Sciences Journal, vol. 29 (12), pp.1600-1604, 2014.

[17] E. Glagolev, L. Suleimanova and V. Lesovik "High reaction activity of nano-size phase of silica composite binder," J. International Journal of Environmental and Science Education, vol. 11(18), pp. 12383-12389, 2016.

[18] L.A. Suleymanova, V.S. Lesovik, K.R. Kondrashev, K.A. Suleymanov and N.P. Lukuttsova "Energy efficient technologies of production and use non-autoclaved aerated concrete," International Journal of Applied Engineering Research, vol. 10(5), pp. 12399-12406, 2015.

[19] R.V. Lesovik, S.V. Klyuyev, A.V. Klyuyev, A. V. Netrebenko and A.V. Durachenko "High-strength fiber-reinforced concrete containing technogenic raw materials and composite binders with use of nanodispersed powder," J. Research Journal of Applied Sciences, vol. 9. (12), pp. 1153-1157, 2014.

[20] K.A. Kara "Study of the grindability of quartz-containing additives as a component of composite binders," J. Bulletin of BSTU named after V.G. Shukhov, vol. 5, pp. 45-52, 2016.

[21] V.S. Lesovik, N.I. Alfimova and P.V. Trunov "Reduction of energy consumption in manufacturing the fine ground cement," J. Research Journal of Applied Sciences, vol. 9. (11), pp. 745-74, 2014. 